\title{
Efeitos de Tipos, Doses e Incorporação de Calcário sobre Características Agronômicas e Fisiológicas do Capim-Tobiatã (Panicum maximum Jacq.) ${ }^{1}$
}

\author{
Pedro Henrique de Cerqueira Luz², Valdo Rodrigues Herling², Gustavo José Braga ${ }^{3}$, \\ Godofredo César Vitti ${ }^{4}$, César Gonçalves de Lima ${ }^{5}$
}

\begin{abstract}
RESUMO - Numa pastagem degradada de capim-Tobiatã (Panicum maximum Jacq cv. Tobiatã), em Pirassununga - SP, instalou-se um experimento para verificar os efeitos de doses e tipos de calcário com ou sem incorporação, sobre o perfilhamento, a cobertura vegetal e a produtividade da pastagem durante seis cortes no período de 1996 a 1997. A produção de matéria seca não respondeu a tipos e doses de calcário, no entanto, a prática da incorporação com grade mostrou-se efetiva e, no tocante aos cortes, houve acréscimo de produção no verão e redução no inverno. A cobertura vegetal apresentou 72,8\% de ocupação para planta forrageira e indicou tendência de menores áreas de solo descoberto nos tratamentos com calcário calcinado.
\end{abstract}

Palavras-chave: calagem, cobertura vegetal, matéria seca, meristema apical, perfilhamento

\section{Effects of Types, Levels and Incorporation of Limestone on Agronomical and Physiological Characteristics of Tobiatã Grass (Panicum maximum Jacq. cv. Tobiatã)}

\begin{abstract}
In a degraded pasture of Tobiatã grass (Panicum maximum Jacq cv. Tobiatã), in Pirassununga - SP, an experiment was carried out to observe the effects of levels and types of limestone with or without incorporation on the tillering, ground cover and pasture productivity during six cuts from 1996 to 1997. There was no response in the dry matter yield to by the levels and types of limestone, however the practice of limestone incorporation using harrow was effective, and based in the cuts there was an increase of dry matter production in the summer and reduction in the winter. The ground cover presented $72.8 \%$ of occupation by the forage grass and it indicated a trend of bare ground in the treatments with calcinated limestone.
\end{abstract}

Key Words: apical meristem, dry matter, liming, ground cover, tillering

\section{Introdução}

A degradação de pastagens é o processo evolutivo da perda do vigor, da produtividade e da qualidade da planta, não superando os efeitos nocivos de pragas, doenças e invasoras, culminando com a degradação avançada dos recursos naturais, em razão de manejos inadequados. Métodos físicos e químicos associados ao suprimento adequado de corretivos e fertilizantes, aplicados na superfície ou incorporados, são considerados prioritários nos estudos de recuperação de pastagens.

Segundo QUAGGIO (1985), há necessidade de incorporação do calcário, pois o preparo do solo normalmente é superficial e, portanto, não consegue proporcionar adequada mistura do corretivo com o solo. Dessa forma, o fato de se utilizarem corretivos mais ou menos reativos implica em diferente predisposição de resposta da planta. As gramíneas com hábito de crescimento estolonífero e/ou rizomatoso possibilitam melhor eficiência do processo de incorporação do corretivo, em relação às de crescimento cespitoso, como é o caso do capim-Tobiatã (VITTI e LUZ, 1997).

Sob o ponto de vista da recuperação da pastagem, considera-se importante a retomada da produtividade, que está relacionada com a porcentagem de cobertura vegetal do solo. O comportamento desta variável da pastagem está intimamente relacionado com a área de solo descoberto, que decresce com o aumento da área ocupada pela planta forrageira, enquanto a planta daninha permanece constante. MARTINS SOBRINHO (1997), estudando os efeitos de doses e tipos de calcário sobre a cobertura vegetal do solo, não obteve respostas significativas, porém mostrou, ao longo do experimento, que o aumento da área ocupada pela planta forrageira

\footnotetext{
1 Projeto financiado pela Fapesp - Proc. no 95/3795-4.

2 Professor Doutor do Depto. de Zootecnia da FZEA/USP - Pirassununga - SP. E.mail: phcerluz@usp.br; vrherlin@usp.br

${ }^{3}$ Aluno de Mestrado da FZEA/USP - Pirassununga - SP. E.mail: gubraga@ abelha.zoot.usp.br

${ }^{4}$ Professor Titular do Depto. de Ciência do Solo da ESALQ/USP - Piracicaba - SP. E.mail: gcvitti@ carpa.ciagri.usp.br

5 Professor Doutor do Depto. de Ciências Básicas da FZEA/USP - Pirassununga - SP. E.mail: cegdlima@usp.br
} 
acarretou diminuição na área de solo descoberto, ao passo que as plantas invasoras permaneceram constantes.

O estudo da correção do solo para gramíneas, em termos da elevação da saturação por bases (V), deve considerar seu potencial de resposta à calagem, podendo ser dividida em três grupos, sendo as do primeiro as espécies e cultivares mais exigentes, como é o caso do capim-Tobiatã, que os autores sugerem elevar a V a $70 \%$ na implantação e a $60 \%$ na manutenção (WERNER et al., 1996).

RUGGIERI et al. (1994) avaliaram o efeito de algumas práticas de manejo sobre a recuperação de uma pastagem degradada de capim-Colonião, em que as mais altas produções de matéria seca foram obtidas com os tratamentos gradagem + corretivo + fertilizante (NPK) e corretivo + fertilizante (NPK), não havendo diferença significativa entre essas duas práticas; efeito este que ocorreu devido ao uso associado de corretivos e fertilizantes. Portanto, não houve efeito da gradagem sobre a produção de matéria seca, mas sim sobre o controle das plantas invasoras.

Em um estudo de estratégias de recuperação de uma pastagem de Brachiaria decumbens Stapf, foi encontrado resultado desfavorável ao uso de gradagem exclusiva, comparada ao fornecimento de macro e micronutrientes, sobre a produção de matéria seca acumulada no primeiro ano, porém semelhante à testemunha no segundo ano (SOARES FILHO, 1991). A ação da grade, sob o ponto de vista da incorporação de insumos e danos à planta forrageira, pode levar a diferentes resultados, dependendo do tipo de solo, do hábito de crescimento da planta forrageira e das dimensões e condições de operação da grade. No caso de uma espécie de crescimento rizomatoso e/ou estolonífero, em solo arenoso, usando-se uma grade aradora (por exemplo 14 discos de 24"), conduzirá à maior mobilização mecânica do solo e, portanto, melhor incorporação do insumo, porém certamente provocará danos à planta forrageira. Por outro lado, incorporação leve (grade de 16 discos de 16") em um solo argiloso provavelmente não será prejudicial ao desenvolvimento da planta.

WERNER et al. (1979), testando dois níveis de calagem (1,5 e 3,4 t/ha de calcário magnesiano), em uma pastagem estabelecida de capim-Colonião, por três anos consecutivos, verificaram não haver resposta sobre a produção de matéria seca, inclusive com efeito depressivo no $2 \underline{o}$ ano do experimento. $\mathrm{Na}$ mesma linha de pesquisa, FERRARI NETO et al. (1994), estudando as limitações nutricionais do ca-
pim-Colonião, indicaram que a omissão de Ca e $\mathrm{Mg}$, bem como a adição de calcário para elevar a $\mathrm{V}$ a $60 \%$, não conduziram a resposta sobre a produção de matéria seca do capim.

Em um estudo com oito cultivares de Panicum maximum Jacq., CECATO et al. (1996) observaram que a cultivar Tobiatã, no período do verão, apresentou valores de matéria seca total e proteína bruta da ordem de $6.988 \mathrm{~kg} / \mathrm{ha}$ e $11,60 \%$, respectivamente. Para o período de inverno, quando foram realizados dois cortes, os valores foram $2.916 \mathrm{~kg} / \mathrm{ha}$ de matéria seca total e $9,58 \%$ de proteína bruta. A produção de inverno correspondeu a $29,4 \%$ do total produzido naquele ano. PEDREIRA (1973), ao avaliar o crescimento estacional do capim-Colonião, constatou que a participação da produção de verão deste capim chegou a um máximo de $92,3 \%$.

Os limites nutricionais, avaliados para o capimColonião, mostraram que a ausência de Ca e $\mathrm{Mg}$ no solo não afetou a densidade de perfilhos, e a adição de calcário, para elevar a saturação por bases a $60 \%$, não influenciou o número de perfilhos da planta FERRARI NETO et al. (1994).

Desse modo, o objetivo do estudo foi verificar os efeitos de tipos e doses de calcário, com e sem incorporação, sobre algumas características agronômicas e fisiológicas do capim-Tobiatã (Panicum maximum Jacq. cv. Tobiatã), em uma pastagem degradada.

\section{Material e Métodos}

O experimento foi instalado em Latossolo Vermelho escuro, argiloso, distrófico, localizado no Campus da USP de Pirassununga - SP, latitude sul $21^{\circ} 59^{\prime}$, longitude oeste $47^{\circ} 26^{\prime}$, a 634 m de altitude. $\mathrm{O}$ clima da região, de acordo com a classificação de Köeppen, é do tipo Cwa: temperado chuvoso, com inverno seco e verão quente e chuvoso (OLIVEIRA e PRADO, 1984).

Na análise química de caracterização do solo, observou-se: $\mathrm{V} \%=31 ; \mathrm{pH}_{\mathrm{CaCl} 2}=4,1 ; \mathrm{Ca}=12,9 \mathrm{mmol}_{\mathrm{c}} / \mathrm{dm}^{3}$; $\mathrm{Mg}=6,3 \mathrm{mmol}_{\mathrm{c}} / \mathrm{dm}^{3} ; \mathrm{Al}=4,5 \mathrm{mmol}_{\mathrm{c}} / \mathrm{dm}^{3} ; \mathrm{m}=22 \%$; e CTC $=62,4 \mathrm{mmol}_{\mathrm{c}} / \mathrm{dm}^{3}$. Utilizou-se uma pastagem degradada de Panicum maximum Jacq. cv. Tobiatã, formada há cerca de treze anos.

Os tratamentos consistiram de dois tipos de calcário, com duas doses. As dosagens empregadas foram determinadas de acordo com o método de elevação da saturação por bases (Van RAIJ, 1981). Os tratamentos foram: testemunha; calcário calcinado 
966 Rev. bras. zootec.

( $\mathrm{V}=40 \%)$; calcário calcinado $(\mathrm{V}=80 \%)$; calcário tradicional $(\mathrm{V}=40 \%)$; e calcário tradicional $(\mathrm{V}=80 \%)$. Estudaram-se ainda duas formas de aplicação dos calcários: aplicado em cobertura e com incorporação, em metade das subparcelas, utilizando-se uma grade "leve", com 16 discos de 16", na posição destravada, incorporando o calcário de modo superficial, aproximadamente a $5,0 \mathrm{~cm}$ de profundidade.

$\mathrm{O}$ delineamento experimental adotado foi em blocos ao acaso e o experimento em parcelas subdivididas, em que o tipo e as doses de calcário estudados corresponderam às parcelas e a incorporação, às subparcelas, com quatro repetições. A incorporação foi realizada sempre no lado direito de cada parcela, pela facilidade de manuseio do implemento.

As parcelas experimentais mediam 6,0 metros de largura e 8,0 metros de comprimento, perfazendo um total de $48 \mathrm{~m}^{2}$, sendo subdividida na largura para o fator incorporação, ficando, dessa forma, a subparcela com 3,0 x 8,0 m, obtendo-se uma área de $24 \mathrm{~m}^{2}$. Adotaramse uma bordadura de $0,5 \mathrm{~m}$, em todo o perímetro das subparcelas, e uma faixa de caminhamento de 1,0 m, entre as parcelas no bloco, de forma que cada subparcela ficasse com $14 \mathrm{~m}^{2}$ de área útil.

Os calcários utilizados nas aplicações foram: calcário calcinado ( $45 \%$ de $\mathrm{CaO}, 25 \%$ de $\mathrm{MgO}$, Poder de Neutralização $-\mathrm{PN}=132 \%$, Reatividade $-\mathrm{RE}=$ $100 \%$ e Poder Relativo de Neutralização Total PRNT $=132 \%)$ e calcário tradicional $(43 \%$ de $\mathrm{CaO}$, $9 \%$ de $\mathrm{MgO}, \mathrm{PN}=99,3 \%, \mathrm{RE}=91 \%$ e $\mathrm{PRNT}=90 \%$ ).

A aplicação dos calcários foi feita após rebaixamento da pastagem (Panicum maximum Jacq. cv. Tobiatã) com roçadora, em julho de 1996, com posterior incorporação, sendo que na primavera subsequente, foi feita a uniformização e adubação da pastagem, para a realização de cinco cortes de verão a intervalo de 35 dias, entre cortes, e um corte de inverno. A adubação da pastagem, após uniformização no início do experimento, consistiu de $120 \mathrm{~kg} / \mathrm{ha}$ de $\mathrm{P}_{2} \mathrm{O}_{5}$, $50 \mathrm{~kg} / \mathrm{ha}$ de $\mathrm{N}$ e $\mathrm{K}_{2} \mathrm{O}$. Após cada corte, as parcelas receberam, em cobertura, $50 \mathrm{~kg} / \mathrm{ha}$ de $\mathrm{Ne} \mathrm{K}_{2} \mathrm{O}$, com exceção do $5 \underline{0}$ e $6^{0}$ cortes.

As variáveis analisadas foram produção de matéria seca, cobertura do solo (planta forrageira, solo descoberto e plantas invasoras), número e peso médio de perfilhos e eliminação de meristema apical.

As porcentagens de cobertura vegetal do solo e de solo descoberto foram determinadas visualmente (TOLEDO e SCHULTZE-KRAFT, 1982), em cada subparcela, por meio do lançamento aleatório de um quadrado $\left(0,25 \mathrm{~m}^{2}\right)$.
O perfilhamento também foi avaliado nas subparcelas, em local fixo, usando-se a área de $0,125 \mathrm{~m}^{2}$, ficando a estaca localizada em seu centro. Após a contagem dos perfilhos, fez-se o corte da touceira, que, levada à estufa à $65^{\circ} \mathrm{C}$, por 72 horas e pesada, possibilitou a determinação do peso seco da touceira e do peso seco médio de cada perfilho. Uma semana após a realização do corte, realizou-se a contagem de perfilhos decapitados, calculando-se a respectiva porcentagem.

Os cortes foram realizados à altura aproximada de $20 \mathrm{~cm}$ do solo de forma manual, sendo a matéria verde pesada imediatamente após o corte. O teor de matéria seca foi determinado por meio de secagem, em estufa com ventilação forçada a $65^{\circ} \mathrm{C}$, por 72 horas, da amostra de forragem retirada do material cortado de cada subparcela. Pela multiplicação do teor de matéria seca e da produção de matéria verde, calculou-se a produção de matéria seca, a $65^{\circ} \mathrm{C}$, por área (kg MS/ha), de acordo com a ASSOCIATION OF OFFICIAL ANALITICAL OF CHEMISTS AOAC (1975).

Durante a realização do experimento, foram monitorados os dados climatológicos, como temperatura e pluviosidade, por meio da estação meteorológica informatizada localizada no setor de Ciências Agrárias da Faculdade de Zootecnia e Engenharia de Alimentos do Campus da USP de Pirassununga.

\section{Resultados e Discussão}

O tipo e as doses de calcário testados não tiveram influência sobre a produção de matéria seca do capim-Tobiatã (Tabela 1), concordando com os resultados obtidos por WERNER et al. (1979) e FERRARI NETO et al. (1994). No entanto, a incorporação com grade, do $1 \underline{0}$ ao $6 \underline{0}$ corte, 4 a 11 meses após a calagem, mostrou-se efetiva $(\mathrm{P}<0,05)$, com maiores produções $(2.046,3 \mathrm{~kg} / \mathrm{ha})$ que na condição não-incorporada (1.926,8 kg/ha). SOARES FILHO (1991), em experimento com braquiária, submetida à incorporação de calcário com grade aradora, não encontrou efeito significativo sobre a produção de matéria seca, assim como RUGGIERI et al. (1994), avaliando a recuperação de uma pastagem de capim-Colonião, submetida a diferentes práticas de manejo.

A produção total média de matéria seca dos seis cortes realizados foi de $11.919,1 \mathrm{~kg} / \mathrm{ha}$, concentrada nos cortes de verão (Tabela 1), com o total médio de $11.054,5 \mathrm{~kg} / \mathrm{ha}$, sendo superior aos resultados obtidos por WERNER et al. (1979). A produção atingida nos cortes de verão correspondeu a $92,7 \%$ da produção 
LUZ et al.

Tabela 1 - Produção de matéria seca (kg MS/ha) do capim-Tobiatã sob tipos e doses de calcários e incorporação, nas diferentes épocas de corte

Table 1 - Dry matter yield ( $\mathrm{kg} \mathrm{DM} / \mathrm{ha}$ ) of Tobiatã grass on types and levels of limestone and incorporation, at different cut dates

\begin{tabular}{|c|c|c|c|c|c|c|c|}
\hline \multirow[t]{2}{*}{$\begin{array}{l}\text { Fator } \\
\text { Factor }\end{array}$} & \multirow[b]{2}{*}{$\begin{array}{c}\text { Corte } \\
\text { Cut }\end{array}$} & \multicolumn{5}{|c|}{$\begin{array}{c}\text { Tratamento } \\
\text { Treatment }\end{array}$} & \multirow[t]{2}{*}{$\begin{array}{l}\text { Média } \\
\text { Mean }\end{array}$} \\
\hline & & $\begin{array}{c}\text { Controle } \\
\text { Control }\end{array}$ & $\begin{array}{l}\text { Calc. } 40 \\
\text { Calc. } 40\end{array}$ & $\begin{array}{l}\text { Calc. } 80 \\
\text { Calc. } 80\end{array}$ & $\begin{array}{l}\text { Trad. } 40 \\
\text { Trad. } 40\end{array}$ & $\begin{array}{l}\text { Trad. } 80 \\
\text { Trad. } 80\end{array}$ & \\
\hline & $\begin{array}{c}1 \underline{\text { o }} \\
05 / 11 / 96\end{array}$ & $1.480,2$ & $1.555,6$ & $1.484,7$ & $1.538,8$ & $1.548,0$ & $1.521,5^{\mathrm{d}}$ \\
\hline & $\begin{array}{c}2 \frac{\mathrm{o}}{12 / 12 / 96} \\
12 / 9\end{array}$ & $1.754,4$ & $1.845,1$ & $1.690,8$ & $1.809,4$ & $1.821,9$ & $1.784,3^{\mathrm{c}}$ \\
\hline & $\begin{array}{c}3{ }^{\mathrm{o}} \\
20 / 01 / 97\end{array}$ & $3.737,2$ & $3.660,7$ & $3.331,1$ & $3.575,6$ & $3.870,4$ & $3.635,0^{\mathrm{a}}$ \\
\hline & $\begin{array}{c}40 \\
24 / 02 / 97\end{array}$ & $2.497,2$ & $2.532,3$ & $2.144,7$ & $2.373,0$ & $2.356,5$ & $2.380,7^{\mathrm{b}}$ \\
\hline & $\begin{array}{c}5 \underline{\mathrm{o}} \\
02 / 04 / 97\end{array}$ & $1.824,1$ & $1.792,1$ & $1.558,7$ & $1.741,8$ & $1.748,5$ & $1.733,0^{\mathrm{cd}}$ \\
\hline & $\begin{array}{l}\text { Verão } \sum \\
\text { Summer } \sum\end{array}$ & 11.293 & 11.385 & 10.210 & 11.038 & 11.345 & $11.054,5$ \\
\hline & $\begin{array}{c}6^{\underline{o}} \\
11 / 06 / 97 \\
\end{array}$ & 895,9 & 877,7 & 792,8 & 869,5 & 887,0 & $864,6^{\mathrm{e}}$ \\
\hline \multirow[b]{2}{*}{$\begin{array}{l}\text { Incorporação } \\
\text { Incorporation }\end{array}$} & $\begin{array}{l}\text { Com } \\
\text { With }\end{array}$ & $2.067,3$ & $2.164,0$ & $1.913,2$ & $2.041,1$ & $2.045,8$ & $2.046,3^{\mathrm{A}}$ \\
\hline & $\begin{array}{c}\text { Sem } \\
\text { Without }\end{array}$ & $1.995,7$ & $1.923,8$ & $1.754,4$ & $1.928,2$ & $2.031,7$ & $1.926,8^{\mathrm{B}}$ \\
\hline $\begin{array}{l}\text { Média geral } \\
\text { Overall mean }\end{array}$ & & $2.031,5^{\mathrm{a}}$ & $2.043,9^{\mathrm{a}}$ & $1.833,8^{\mathrm{a}}$ & $1.984,7^{\mathrm{a}}$ & $2.038,7^{\mathrm{a}}$ & $1.986,5$ \\
\hline
\end{tabular}

Médias, na linha e coluna, seguidas por letras diferentes diferem $(P<0,05)$ pelo teste Tukey.

Means, within rows and column, followed by different letters differ $(P<.05)$ by Tukey test.

total, indicando alta estacionalidade, assim como aquelas obtidas por CECATO et al. (1996) e PEDREIRA (1973), que avaliaram o crescimento estacional do capim-Colonião.

A Figura 1 contém os dados climáticos por decêndios, obtidos no período de realização do experimento, relativos ao índice pluviométrico e a temperaturas máxima, mínima e média. Nos últimos decêndios dos meses de dezembro (1996) e janeiro (1997), ocorreu elevada pluviosidade aliada a altas temperaturas, o que possivelmente contribuiu para as altas produções $(\mathrm{p}<0,05)$ da gramínea nos $3^{\underline{0}}$ e $4^{\circ}$ cortes de verão (Tabela 1), 6 e 7 meses após a calagem, conduzindo para a alta estacionalidade observada no comportamento da produção. O mês de

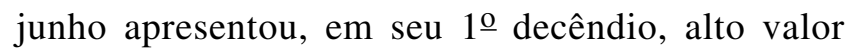
pluviométrico $(100 \mathrm{~mm})$, sendo considerado elevado para a época do ano, porém com queda sensível na temperatura, o que certamente foi determinante para

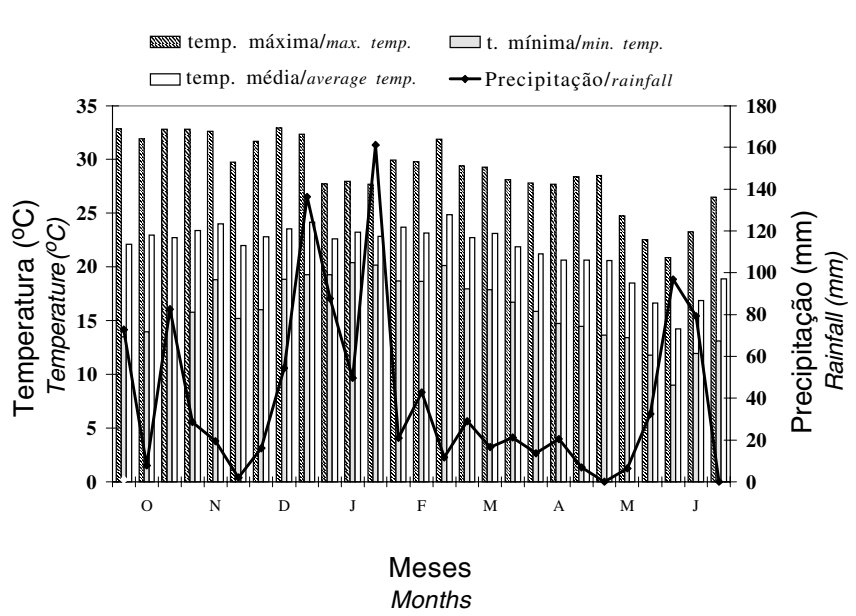

Figura 1 - Dados climáticos médios nos três decêndios dos meses entre outubro/96 a Junho/97.

Figure 1 - Average climatic data in the three periods of ten days from October 1996 to June 1997. 
968 Rev. bras. zootec.

a baixa produção do capim.

Os dados de cobertura vegetal (Tabela 2) revelaram ocupação média de $72,3 \%$ para a planta forrageira e $4,7 \%$ para plantas invasoras, restando 23,0\% para o solo descoberto. A análise estatística não revelou diferença significativa $(\mathrm{P}>0,05)$ para a área de solo descoberto, obtendo-se menor valor $(21,06 \%)$ para a média dos tratamentos com calcário calcinado, em relação ao tradicional $(24,52 \%)$, comportamento semelhante ao obtido por MARTINS SOBRINHO (1997).

Constatou-se que o número e peso médio de perfilhos apresentaram comportamento inversamente proporcional $(r=-0,59)$, semelhante ao obtido por KATAOKA et al. (1991), estudando sete cultivares de capim de Rhodes; HERLING (1995), com as cultivares Colonião e Centenário; e ANDRADE (1987), com o capim-Colonião, bem como as correlações entre produção de matéria seca e número de perfilhos $(r=-0,52)$, de acordo com a Figura 2. Por outro lado, a correlação entre a produção e o peso médio de perfilhos (Figura 3 ) foi positiva e significativa $(r=+0,98)$, indicando que o peso médio dos perfilhos é determinante sobre a produção de matéria seca de uma pastagem em fase de recuperação. ANDRADE (1987) observou que a produção de

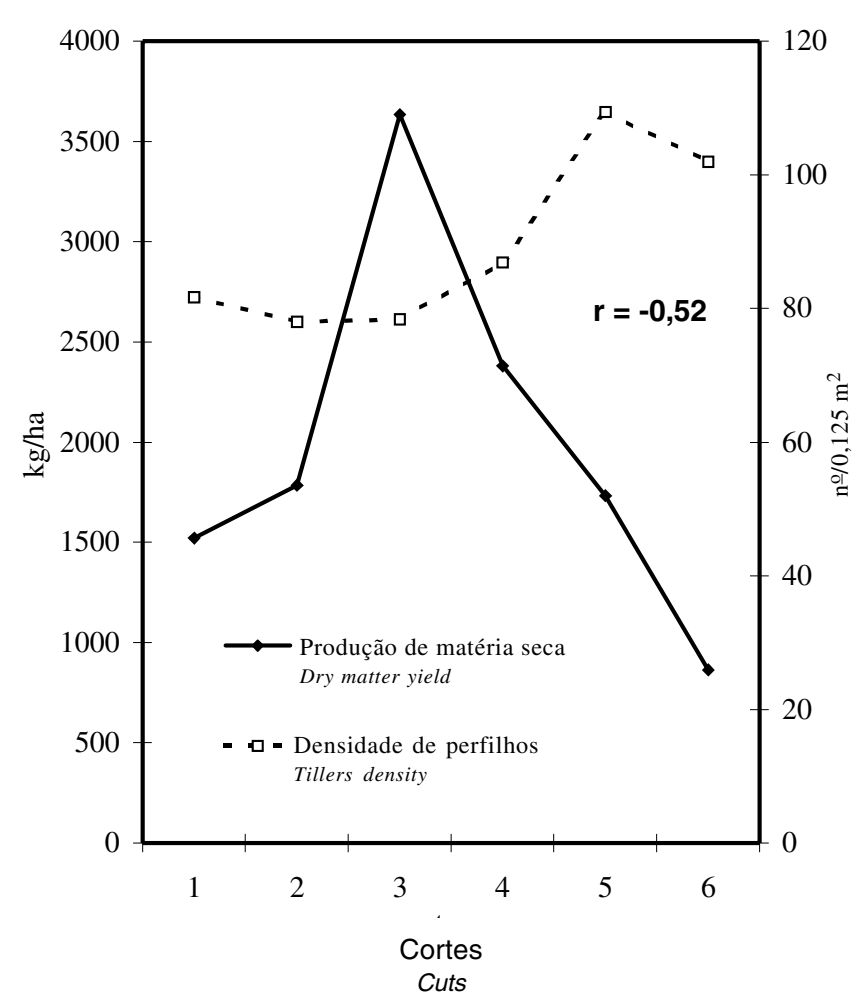

Figura 2 - Produção de matéria seca $(\mathrm{kg} / \mathrm{ha})$ e densidade de perfilhos ( $\mathrm{n}$ \% $\left./ 0,125 \mathrm{~m}^{2}\right)$.

Figure 2 - Dry matter yield (kg/ha) and tiller density (n./.125 $\left.\mathrm{m}^{2}\right)$.

Tabela 2 - Cobertura vegetal da pastagem e perfilhamento do capim-Tobiatã

Table 2 - Vegetal ground cover of the pasture and tillering of Tobiatã grass

\begin{tabular}{|c|c|c|c|c|c|c|c|}
\hline $\begin{array}{l}\text { Variável } \\
\text { Variable }\end{array}$ & & & & $\begin{array}{l}\text { Corte } \\
\text { Cut }\end{array}$ & & & $\begin{array}{l}\text { Média } \\
\text { Mean }\end{array}$ \\
\hline $\begin{array}{l}\text { Cobertura vegetal do solo (\%) } \\
\text { Ground cover }\end{array}$ & $1^{\mathrm{o}}$ & $2^{\underline{o}}$ & $3^{\underline{o}}$ & $4 \mathrm{O}$ & $5 \underline{0}$ & $6^{0}$ & \\
\hline $\begin{array}{l}\text { Planta forrageira } \\
\text { Grass plant }\end{array}$ & $74,8^{\mathrm{b}}$ & $68,4^{b c}$ & $85,7^{\mathrm{a}}$ & $75,5^{\mathrm{b}}$ & $68,1^{\mathrm{c}}$ & $61,3^{\mathrm{d}}$ & 72,3 \\
\hline $\begin{array}{l}\text { Plantas invasoras } \\
\text { Weeds }\end{array}$ & $4,2^{\mathrm{a}}$ & $5,9^{\mathrm{a}}$ & $4,7^{\mathrm{a}}$ & $4,3^{\mathrm{a}}$ & $4,9^{\mathrm{a}}$ & $4,2^{\mathrm{a}}$ & 4,7 \\
\hline $\begin{array}{l}\text { Solo descoberto }(\%) \\
\text { Bare ground } \\
\end{array}$ & $21,0^{\mathrm{cd}}$ & $25,7^{b c}$ & $9,6 \mathrm{e}$ & $20,3^{\mathrm{d}}$ & $27,0^{\mathrm{b}}$ & $34,5^{\mathrm{a}}$ & 23,0 \\
\hline $\begin{array}{l}\text { № de perfilhos }\left(0,125 \mathrm{~m}^{2}\right) \\
N \text {. of tillers }\left(0.125 \mathrm{~m}^{2}\right)\end{array}$ & $81,7^{\mathrm{b}}$ & $78,0^{\mathrm{b}}$ & $78,4^{\mathrm{b}}$ & $86,8^{\mathrm{b}}$ & $109,4^{\mathrm{a}}$ & $102,0^{\mathrm{a}}$ & 89,4 \\
\hline $\begin{array}{l}\text { Eliminação meristema apical (\%) } \\
\text { Elimination of apical meristem (\%) }\end{array}$ & $3,2^{b}$ & $3,5^{b}$ & $13,0^{\mathrm{a}}$ & $3,7^{b}$ & $3,4^{b}$ & $6,4^{b}$ & 5,54 \\
\hline $\begin{array}{l}\left.\text { Peso do perfilho (g MS/ } 0,125 \mathrm{~m}^{2}\right) \\
\text { Tiller weight }\left(\mathrm{g} D M / 0.125 \mathrm{~m}^{2}\right)\end{array}$ & $0,24^{\mathrm{cd}}$ & $0,33^{b c}$ & $0,67^{\mathrm{a}}$ & $0,40^{\mathrm{b}}$ & $0,24^{\mathrm{cd}}$ & $0,17^{\mathrm{d}}$ & 0,34 \\
\hline
\end{tabular}

Médias, na linha, seguidas por letras diferentes diferem $(P<0,05)$ pelo teste Tukey.

Means, within a row, followed by different letters differ $(P<.05)$ by Tukey test. 


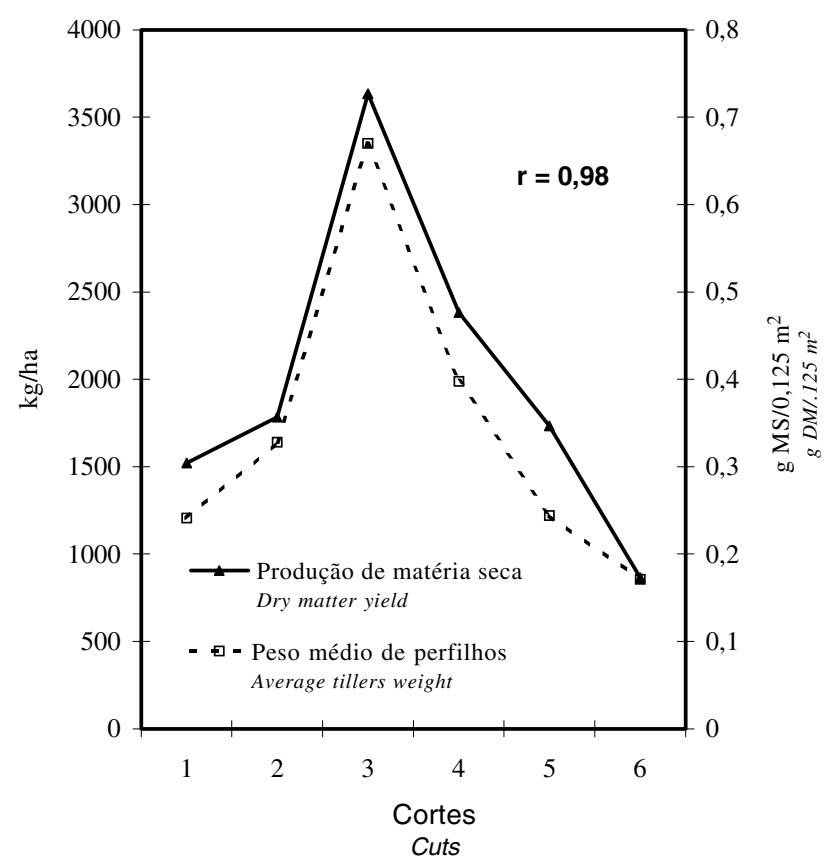

Figura 3 - Produção de matéria seca $(\mathrm{kg} / \mathrm{ha})$ e peso médio de perfilhos ( $\mathrm{n} \% 0,125 \mathrm{~m}^{2}$ ).

Figure 3 - Dry matter yield $(\mathrm{kg} / \mathrm{ha}$ ) and average tillers weight (n./0.125 $\mathrm{m}^{2}$ ).

matéria seca teve maior correlação com o peso médio de perfilhos. A densidade de perfilhos atingiu maior valor no tratamento tradicional $\mathrm{V}=40 \%$, que apresentou média nos seis cortes de 103,9 perfilhos $/ 0,125 \mathrm{~m}^{2}$, porém com menor valor para peso médio de perfilhos de $0,316 \mathrm{~g} \mathrm{MS} / 0,125 \mathrm{~m}^{2}$, não sendo significativa a diferença entre tratamentos na análise de variância, confirmando novamente o comportamento antagônico entre essas variáveis. Tal resultado foi semelhante ao de FERRARINETO et al. (1994), que avaliaram os efeitos da ausência de $\mathrm{Ca}$ e $\mathrm{Mg}$ no solo e a calagem, para elevar a $\mathrm{V}=60 \%$ sobre a densidade de perfilhos do capim-Colonião. A incorporação do calcário não afetou a densidade de perfilhos.

A eliminação do meristema apical não respondeu aos tipos e doses de calcário, nem à incorporação, sendo significativo o comportamento entre cortes (Tabela 2), com maior valor no mais produtivo (13,0\% no 3 - corte), seis meses da calagem, da mesma forma que o obtido por FAVORETTO et al. (1987) e COSTA e OLIVEIRA (1997), relatando que a maior eliminação do meristema apical ocorreu no corte mais produtivo, indicando elevação de sua posição no perfilho, em virtude de a planta ter alcançado maior desenvolvimento.

\section{Conclusões}

O capim-Tobiatã não respondeu, em produção de matéria seca, aos tipos e doses de calcário utilizados.

A operação de incorporação com grade implicou em maiores produções de matéria seca na recuperação do capim-Tobiatã.

O comportamento entre densidade e peso médio de perfilhos foi inversamente proporcional, sendo o peso mais determinante na produção de matéria seca que o número deles. A maior eliminação do meristema apical esteve associada à maior produção.

\section{Referências Bibliográficas}

ANDRADE, J.B. Estudo comparativo de três capins da espécie Panicum maximum Jacq. Piracicaba, SP: ESALQ, 1987. 131p. Dissertação (mestrado em Agronomia) - Escola Superior de Agricultura “Luiz de Queiroz”, Universidade de São Paulo, 1987. ASSOCIATION OF OFFICIAL ANALITICAL OF CHEMISTS - AOAC. 1975. Official methods of analysis. 12. ed. Washington D.C. $1094 \mathrm{p}$.

CECATO, U., BARBOSA, M.A.A.F., SAKAGUTI, E.S. et al. Avaliação de cultivares de Panicum maximum Jacq. In: REUNIÃO ANUAL DA SOCIEDADE BRASILEIRA DE ZOOTECNIA, 33, 1996, Fortaleza. Anais... Fortaleza: SBZ, 1996, p.109-111.

COSTA, N.L., OLIVEIRA J.R.C. Produção de forragem e composição química de Panicum maximum cv. Tobiatã em diferentes idades de cortes. In: REUNIÃO ANUAL DA SOCIEDADE BRASILEIRA DE ZOOTECNIA, 34, 1997, Juiz de Fora. Anais.... Juiz de Fora: SBZ, 1997, p. 222-224.

FAVORETTO, V., TONINI JR, R., REIS, R.A. et al. 1987. Efeito da altura e frequência de corte sobre a produção, composição bromatológica e vigor de rebrota do capimColonião. Pesq. Agropec. Bras., 22(11/12):1279-1285.

FERRARI NETO, J., FAQUIN, V., VALE, F.R. et al. 1994. Limitações nutricionais do Colonião (Panicum maximum Jacq.) e da Braquiária (Brachiaria decumbens Stapf), em amostras de um latossolo do noroeste do Paraná: I. Produção de matéria seca e perfilhamento. R. Soc. Bras. Zootec., 23(4):538-551.

HERLING, V.R. Efeitos de níveis de nitrogênio sobre algumas características fisiológicas e qualitativas dos cultivares Colonião e Centenário (Panicum maximum Jacq.). Jaboticabal, SP: FCAV, 1995. 125p. Tese (Doutorado em Zootecnia) - Faculdade de Ciências Agrárias e Veterinárias - Campus de Jaboticabal - Universidade Estadual Paulista, 1995.

KATAOKA, M., IBARAKI, K., TOKUNAGA, H. 1991. Population regulation of Rhodesgrass cultivars in sward conditions. 2. Tiller density. J. Applied Ecology, 28(3):842-854.

MARTINS SOBRINHO, E.O. Efeitos de tipos e doses de calcário em pastagem de capim-Tobiatã (Panicum maximum Jacq). Pirassununga, SP: FZEA, 1997. 51p. Dissertação (Mestrado em Zootecnia) - Faculdade de Zootecnia e Engenharia de Alimentos - Campus de Pirassununga/Universidade de São Paulo, 1997.

OLIVEIRA, J.B., PRADO, H. 1984. Levantamento pedológico do estado de São Paulo: quadrícula de São Carlos. II 
970 Rev. bras. zootec.

Memorial descritivo. Boletim técnico do IAC, no 98. 188p.

PEDREIRA, J.V.S. 1973. Crescimento estacional dos capins Colonião Panicum maximum Jacq., Gordura Melinis minutiflora Pal de Beauv, Jaraguá Hyparrhenia rufa (Ness) Stapf. e Pangola de Taiwan A-24 Digitaria pentzii Stent. Bol. Ind. Anim., 30(1):59-145.

QUAGGIO, J.A. Respostas das culturas à calagem. In: SEMINÁRIO SOBRE CORRETIVOS AGRÍCOLAS, Piracicaba, 1985. Anais... Campinas, Fundação Cargill, 1985, p.123-157.

Van RAIJ, B. 1981. Avaliação da fertilidade do solo. Piracicaba, Associação Brasileira para Pesquisa da Potassa e do Fosfato. 142p.

RUGGIERI, A.C., GUIM, A., ANDRADE, P. et al. Recuperação de uma pastagem degradada de capim-Colonião (Panicum maximum Jacq.) submetidas a diferentes práticas de manejo. In: REUNIÃO ANUAL DA SOCIEDADE BRASILEIRA DE ZOOTECNIA, 31, 1994, Maringá, Anais... Maringá: SBZ, 1994. p.376.

SOARES FILHO, C.V. Variação sazonal de parâmetros bioquímico-fisiológicos em Brachiaria decumbens estabelecida em pastagem. Piracicaba, SP: ESALQ, 1991. 110p. Dissertação (Mestrado em Zootecnia) - Escola Superior de Agricultura Luiz de Queiroz/Universidade de São Paulo, 1991.

TOLEDO, J.M., SCHULTZE-KRAFT, R. 1982. Metodologia para la evaluación agronômica de pastos tropicales. In: TOLEDO, J.M. (Ed.) Manual para la evaluácion agronômica. Centro Interamericano de Agricultura Tropical - CIAT. p.91-110.
VITTI, G.C., LUZ, P.H.C. Calagem e uso do gesso agrícola em pastagens. In: SIMPÓSIO SOBRE ECOSSISTEMA DE PASTAGENS, 3, 1997, Jaboticabal. Anais.... Jaboticabal: FCAV/UNESP, 1997, p.63-111.

WERNER, J.C., MONTEIRO, F.A., CARRIEL, J.M. 1979. Efeitos da calagem em capim-Colonião (Panicum maximum Jacq.) estabelecido. Bol. Ind. Anim., 36(2):247-254.

WERNER, J.C., PAULINO, V.T., CANTARELLA, H. et al. 1996. Forrageiras, In: Van RAIJ, B., CANTARELLA, H., QUAGGIO, J.A. et al. (Eds.) Recomendações de adubação e calagem para o Estado de São Paulo. Campinas: Instituto Agronômico de Campinas \& Fundação IAC. 2.ed. p.263-273.

Recebido em: 01/06/1998

Aceito em: 22/11/1999 